\title{
APPLICATION OF MAXIMUM LIKELIHOOD TO A BIVARIATE TWO-LIMIT TOBIT MODEL FOR ESTIMATION OF RURAL RETAIL SALES POTENTIAL
}

\author{
Thomas R. Harris and J. S. Shonkwiler*
}

\begin{abstract}
A bivariate likelihood function for a two-limit tobit model is developed and applied to the estimation of rural resident shopping pattems. Comparison of results from the univariate and bivariate models shows that parameters are estimated with more precision, and derivatives of conditional expectations are larger under the bivariate procedure. Results suggest rural commercial sector development plans should address a broad array of retail stores in order to capture the interdependencies of retail purchases.
\end{abstract}

\section{INTRODUCTION}

Rural economic development programs traditionally concentrate attention and resources on recruiting and attracting export-oriented goods-producing industries. Local economic development professionals encourage industrial recruitment programs because they can demonstrate that an export industry provides a base for expenditures among existing local economic sectors while generating the economic inputs for further local economic development. Moreover, success in attracting a manufacturing firm is highly visible, the direct employment and income effects are measurable, and abundant media coverage is received for the community's development team.

Nonetheless, industrial recruitment programs are high cost, high risk, and may yield very little payoff. Hansen (1970) found that some rural communities are unsuccessful at industrial recruitment because they have too few resources to attract industries. To attract industries, rural communities with meager resources often grant tax concessions to new or relocating firms, thereby eliminating opportunities for local fiscal gains. This type of industrial recruitment increases the local tax burden because of increased community services to the new industry incurred without an expanding tax base due to the tax moratoria (Tweeten and Brinkman 1976). Moreover, firms that are likely and willing to move to a community if offered sufficient incentives are also likely and willing to leave a community to take advantage of better offers found elsewhere (Winder 1969). The results of a survey conducted by McNamara and Green (1988) show that planning

\footnotetext{
*Professor and Director of the University Center for Economic Development and Professor in the Department of Agricultural Economics at the University of Nevada, Reno, respectively. The research was conducted under funding from University Center for Economic Development and University of Nevada Agricultural Experiment Station Project 219.
} 
commissions continue their emphasis on recruiting export-oriented industries, while the pursuit of alternative economic development strategies, such as local services and retail sector development, is largely overlooked and sometimes neglected.

Expansion of local services and the retail sector addresses the economic development strategy of import substitution. Import substitution seeks to replace goods and services imported from outside the area with local sources of supply (Shaffer 1989). This strengthens linkages within the local economy because expenditures remain inside the local economy instead of being lost as imports. For contemporary and future time periods, local economic development practitioners must be encouraged to give greater balance to their local economic development efforts, including greater emphasis to the development of local services and the retail sector.

In recent years, economists have conducted applied research and extension education programs throughout the nation to help local economic development practitioners estimate the effective performance of their local retail sector. Such estimates have proven useful in building awareness and support for local retail sector development activities. Moreover, estimates of the success or failure of the retail sector in capturing local and outside markets are essential for designing a strategy for local businesses. This paper examines the potential use of a two-limit tobit procedure to incorporate interdependencies between retail sectors and estimate local retail sector expansion potentials. Specific objectives are to review characteristics of the study area (Douglas County, Nevada), to discuss the trade area activity analysis procedures of trade area capture and pull factors, and to discuss the added information obtained from a resident survey and a two-limit tobit procedure for analysis of local retail sector potential.

\section{STUDY AREA}

The study area for this paper is Douglas County, which is located in northwestem Nevada. Douglas County is very unique in that it encompasses the large casino and recreation area of Lake Tahoe and the rural agricultural valley of Minden-Gardnerville (Figure 1).

Because of environmental and water quality concerns, the casino industry cannot expand operations in the South Lake Tahoe area. This limits the future expansion of export recreational employment and income for Douglas County.

With legislative limits on growth in South Lake Tahoe, Douglas County decision makers have concentrated their efforts to expand the local retail sector economy within Douglas County and more specifically within the rural com- 
FIGURE 1

Market Area for Douglas County Households

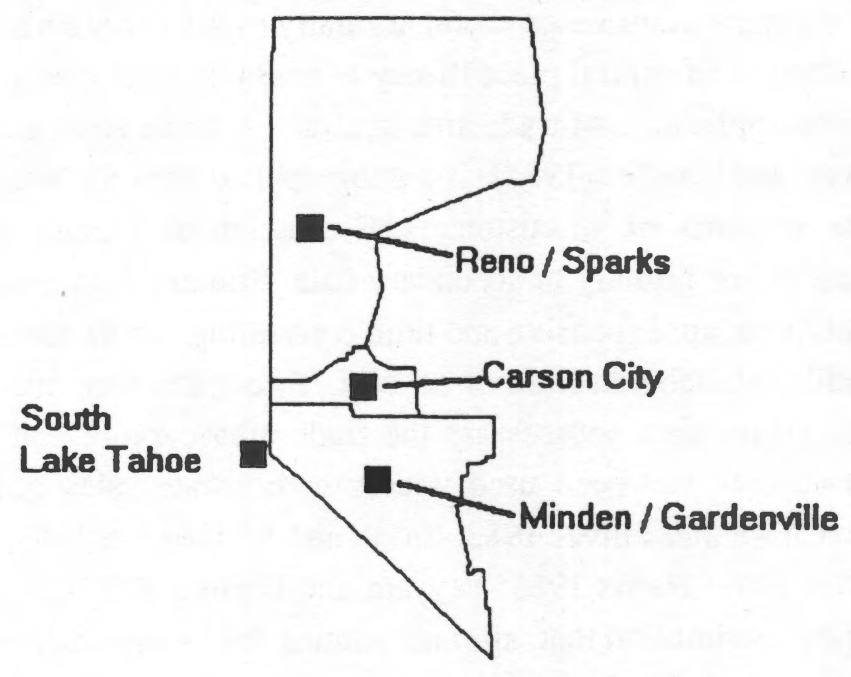

munities of Minden and Gardnerville. Douglas County has the second highest per capita income of all Nevada counties and is approximately 126 percent of the 1990 national per capita income figure (U.S. Department of Commerce 1992). However, Douglas County is adjacent to Carson City (the state capitol) and Washoe County (Reno-Sparks urban area). Being adjacent to these two counties, Douglas County officials requested information on the amount and degree of retail sector sales leakages and suggestions on how to reduce these leakages.

The question of retail sales leakage was of interest to the Douglas County Board of Commissioners since retail sales leakages cost the county tax revenues from sales taxes paid on items purchased outside the county. Also, Douglas County merchants could use the information to identify opportunities for retail business creation and/or expansion in the local economy. With development of additional local retail opportunities, local consumers will have more choices and potentially will be better served.

\section{CENTRAL PLACE THEORY AND RETAIL TRADE ANALYSIS}

Trade area analysis is rooted in central place theory. Central place theory predicts that a hierarchy of communities exists where the number of retail functions performed at a community increases as the size or order of a community increases (King 1984). Central place theory, developed by Christaller (1933) and 
later modified by Losch (1954), conceptualized linkages between population and retail trade functions performed as spatially related. The varieties of retail goods offered by a community depend upon demand and supply conditions locally as well as the distance a consumer would normally travel to obtain a particular good.

The adoption of central place theory to estimate rural commercial sector activity requires application of trade area analysis. A trade area, as defined by Hustedde, Pulver, and Shaffer (1984), is a geographical area for which a commodity captures the majority of its customers. Estimation of a trade area can be performed using either primary or secondary data. Primary data, usually in the form of a questionnaire, are expensive and time consuming, while secondary data sources are readily available at little or no cost. Two trade area analysis procedures that use secondary data sources are the trade area capture and the pull factor. Trade area capture has been used widely to estimate sales potential for local economies (Chase and Pulver 1983; Stone and McConnon 1983; Hustedde et al. 1984; Shaffer 1989; Harris 1985; Tayyem and Darling 1992). Trade area capture is based on the assumption that, after accounting for income differences, local tastes or preferences are similar to that of the state or reference area.

The trade area capture measure is a surrogate estimate for the number of customers or customer equivalents who purchase a specific type of merchandise (merchandise type i) in a given locality. With application to a county, the standard approach used to derive trade area capture is presented by the following equation:

$$
T A C_{i j}=\frac{R S_{i j}}{\frac{R S_{i s}}{P O P_{s}} * \frac{P C I_{j}}{P C I_{s}}}
$$

Where:

$\mathrm{TAC}_{\mathrm{ij}}$ is the trade area capture estimate for merchandise type $\mathrm{i}$ in county $\mathrm{j}$, $R_{i j}$ is total sales of merchandise type $i$ in county $j$,

$\mathbf{R S}$ is is total sales of merchandise type $i$ in state $s$,

POP $_{\mathbf{s}}$ is population in state $\mathrm{s}_{\text {, }}$

$\mathrm{PCl}_{\mathrm{j}}$ is per capita income in county $\mathrm{j}$, and

$\mathbf{P C I}_{\mathbf{s}}$ is per capita income in state $\mathbf{s}$.

Retail sales estimates obtained from the Sales and Marketing Management Magazine (1991) and population and per capita income data from the U.S. Department of Commerce (1992) are substituted into Equation (1) to illustrate how the trade area capture estimate is derived. The result shown in Equation (2) is for Douglas County $(j=d)$ and applies specifically to the "grocery store" ( $i=g$ ) 
category of retail sales for 1990 .

$$
\mathrm{TAC}_{\mathrm{gd}}=17,610
$$

Douglas County's 1990 trade area capture for the grocery store category amounted to 17,610 customer equivalents (i.e., a surrogate for the number of customers including tourists and residents of neighboring counties, etc.). Since the trade area capture is less than Douglas County's population $(28,100)$, it may be judged that the county is not capturing the purchases of its local residents and is losing sales to out-of-county establishments.

The trade area capture estimate is an absolute rather than a relative measure of performance. That is, it measures purchases of both residents and nonresidents. It is therefore difficult to use this measure for making comparisons with regions of different sizes and for assessing trends over time. For these purposes, the pull factor is used. The pull factor explicitly calculates the proportion of the consumers that a county draws from outside its boundaries (i.e., tourists, residents from outside the county, etc.). The pull factor removes the influence of local population changes over time when determining changes in drawing power for a particular county. The pull factor is calculated by dividing the trade area capture estimate by the county population, or:

$$
P F_{i j}=\frac{T A C_{i j}}{P O P_{j}}
$$

Where:

$P F_{i j}$ is the pull factor for merchandise type $i$ in county $j$,

$\mathrm{TAC}_{\mathrm{ij}}$ is the trade area capture estimate of merchandise type $\mathrm{i}$ in county $\mathrm{j}$, and

$\mathrm{POP}_{\mathrm{j}}$ is population in county $\mathbf{j}$.

A pull factor greater than one may be interpreted to mean that the county is attracting a larger number of customer equivalents than would normally be drawn from the local population, assuming their level of purchases were similar to the statewide average. Conversely, a pull factor less than one implies that the retail purchases of local residents are not being captured by the local commercial sector. Using Equation (3), the 1990 pull factor value for grocery stores $(i=g)$ of Douglas County $(j=d)$ is:

$$
\mathrm{PF}_{\mathrm{gd}}=0.6267
$$


Douglas County's 1990 pull factor for the grocery store category was 0.6267. With a pull factor less than one, Douglas County's grocery store sector potentially is losing trade to neighboring counties or elsewhere. From the results of the trade area analysis, there is evidence for possible grocery store development in Douglas County. However, in using trade area capture and pull factor calculations, determinants of local retail trade are not known or analyzed. Therefore, local economic development practitioners may be at a loss when trying to identify factors causing retail sales leakages. With no knowledge of potential socioeconomic factors contributing to local retail sales leakages, formulating activities to strengthen local commercial sector activity or targeting commercial sector industries to develop or relocate in the community may be either incorrect or fall short of anticipated goals.

\section{DETERMINANTS OF FACTORS IN RURAL COMMERCIAL SECTOR MARKET ACTIVITY}

As stated earlier, the lack of encompassing socioeconomic factors that may cause variation in local commercial sector activity is a deficiency in trade area analysis. However, pull factors calculated over time and compared to other communities of similar socioeconomic characteristics help local decision makers evaluate the competitiveness of their local commercial sector. Yanagida et al. (1991) developed an analytical framework for explaining both cross-sectional and intertemporal variations in pull factors for county retail sales in Nebraska. They found that lower retail sales leakages may be attributed to counties that are situated farther from trade centers, have larger federally adjusted gross incomes, and have experienced relatively lower population decreases. Specifically for agriculturally dependent Nebraska counties, the smaller the population of the largest town in the county, the more significant the sales leakage.

Stone (1988) used cross-sectional data to investigate the impacts of shopping malls on rural lowa retail sales. Stone found that if a mall is present in a county, total retail sales for the county increased by $\$ 75$ per additional square foot of mall space. However, when a mall is located outside the county and is within 25 miles of the county seat, total county retail sales decreased by $\$ 4.86$ for each additional square foot of mall space. When a mall is located outside the county and is within 26 to 50 miles of the county seat, county retail sales realized a loss of $\$ 0.61$ for each additional square foot of mall space.

Hamilton (1981) investigated the influence of population size and change on retail sales patterns in Queensland, Australia. Hamilton found that more populated communities achieved higher levels of per capita retail sales than less populated 
communities. However, close proximity to larger trade centers decreased per capita sales significantly. Hamilton's results also showed that declining or slowgrowing communities are more tenacious in holding onto local retail outlets, while faster growing communities are engaged in replacing small shops with large retail outlets.

Henderson (1990) estimated the elasticity of retail sales with respect to rural income. Henderson found that elasticities varied by type of retail business, source of income, and size of community. Henderson concluded that altemative rural development strategies that change the various sources of income to rural communities will yield different retail sales distributions.

Results of trade area and rural retail demand factor analysis have ignored the potential interdependency of retail purchases from different retail store categories. Ignoring possible interdependencies among retail sectors may lead to erroneous estimates of retail sales potentials. For this paper, a two-limit tobit model was developed to incorporate interdependencies among retail sectors and to estimate sales potentials in Douglas County.

\section{TWO-LIMIT TOBIT MODEL}

The two-limit tobit model has been discussed by Nelson (1976) and Maddala (1983). Assume that a normally distributed dependent variable, y, is observed but truncated at both ends of its distribution, and these limits are zero on the left and $\mathrm{L}$ on the right. As Johnson and Kotz (1970) suggest, if the truncation occurs in the extreme tails of the distribution, then the distribution of $y$ may be well approximated by an untruncated normal distribution. This practice is common when estimating systems of share equations, even though the share is constrained to lie between zero and one. Of course, if the analyst observes values at these extremes, then it is likely that the underlying distribution is not normal and that predictions may lie outside the relevant limits.

The likelihood function for the $n^{\text {th }}$ observation $(n=1,2, \ldots, N)$ of the twolimit tobit model is given by

$$
L_{n}=\Phi\left(-\frac{X_{n} \beta}{\sigma}\right)^{D_{0}}\left[\sigma^{-1} \phi\left(\frac{y_{n}-X_{n} \beta}{\sigma}\right)\right]^{D_{1}}\left[1-\Phi\left(\frac{L-X_{n} \beta}{\sigma}\right)\right]^{D_{2}}
$$

where $\Phi(\cdot)$ and $\phi(\cdot)$ represent the standard normal distribution and density functions, respectively. Also, $\beta$ is the regression coefficient, $\sigma$ is the standard deviation, and $X_{n}$ are the independent variables in the model. The exponents $D_{0}, D_{1}$, and $D_{2}$ correspond to whether the observed value of $y_{n}$ is the lower limit, between 
the limits, or the upper limit by taking a value of one; otherwise they are zero. Maximum likelihood estimation is accomplished by maximizing the loglikelihood function over the sample, i.e., maximizing

$$
\sum_{n=1}^{N} \ln L_{n}
$$

Note that the first and last terms on the right side of expression (7) can be interpreted as the probability that $y_{n}=0$ and the probability $y_{n}=L$, respectively. Thus, the probability that $0<y_{n}<L$ is given by

$$
\Phi\left(\frac{L-X_{n} \beta}{\sigma}\right)-\Phi\left(-\frac{X \beta}{\sigma}\right)
$$

and the expected value of yn when in this interval is

$$
\int_{0}^{L} y \sigma^{-1} \phi\left(\frac{y-X_{n} \beta}{\sigma}\right)\left[\Phi\left(\frac{L-X_{n} \beta}{\sigma}\right)-\Phi\left(-\frac{X_{n} \beta}{\sigma}\right)\right]^{-1} d y
$$

Johnson and Kotz (1970) and Maddala (1983) present a formula for expression (8) that only requires evaluating the distribution functions of standard normals. We are interested in (8) because it can be used to evaluate how a change in a conditioning variable $\left(X_{n k}\right)$ affects the expected value of $y_{n}$.

\section{The Bivariate Two-Limit Tobit System}

The likelihood function for the bivariate two-limit tobit model may be obtained by specializing the general approach of Chesher (1985). His focus is on obtaining tests under the null hypothesis of zero error covariances between models of censored or grouped variates. However, Chesher develops an implicit likelihood function under the altemative by inducing correlation between structural equations according to a common random variable.

Let $i=1,2$ index equations in the two-limit tobit system, and assume there is an underlying latent variable $y_{i}^{*}$ such that 


$$
\begin{array}{llrl}
y_{i}=0 \text { if } y_{i}^{*} \leq 0 & & {\left[D_{i 0}=1, \text { otherwise } 0\right]} \\
y_{i}=y_{i}^{*} \text { if } 0<y_{i}^{*}<L & {\left[D_{i 1}=1, \text { otherwise } 0\right]} \\
y_{i}=L \text { if } y_{i}^{*} \leq L & {\left[D_{i 2}=1, \text { otherwise } 0\right]}
\end{array}
$$

and the observation index is understood. The matrix-vector representation of the latent variable system is

$$
\begin{aligned}
& y_{1}^{*}=\alpha_{1}+X_{1} \beta_{1}+\varepsilon+v_{1}=\alpha_{1}+X_{1} \beta_{1}+u_{1} \\
& y_{2}^{*}=\alpha_{2}+X_{2} \beta_{2}+\varepsilon+v_{2}=\alpha_{2}+X_{2} \beta_{2}+u_{2}
\end{aligned}
$$

where $v_{1}, v_{2}$, and $\varepsilon$ are zero mean, mutually independent normal vectors with variances $\sigma_{11}, \sigma_{22}$, and $\lambda$, respectively. Consider writing $u_{1}=e+v_{1}$ and

$$
\begin{aligned}
& u_{2}=e+v_{2} \text { then }\left[u_{1 n} \vdots u_{2 n}\right]^{\}} \text {is } N[0, \Omega] \text { where } \\
& \Omega=\left[\begin{array}{cc}
\sigma_{11}+\lambda & \lambda \\
\lambda & \sigma_{22}+\lambda
\end{array}\right]
\end{aligned}
$$

for all $\mathrm{n}$. In this manner, the common random element $\varepsilon$ induces correlation between the latent structural equations, and if $\lambda=0$ then standard univariate limited dependent variable estimators are suitable.

For the case when $\lambda \neq 0$, more complicated estimators are required. The likelihood function for the two-limit tobit system becomes

$$
\begin{aligned}
L_{n}(\lambda)= & \int_{-\infty}^{\infty} \prod_{i=1}^{2}\left\{\phi\left(-\frac{X_{i n} \beta_{i-\varepsilon}}{\sigma_{i}}\right)^{D_{i 0}}\left[\sigma_{i}^{-1} \cdot\left(\frac{y_{i n}-X_{i n} \beta_{i-\varepsilon}}{\sigma_{i}}\right)\right]^{D_{i 1}}\left[1-\Phi\left(\frac{L-X_{i n} \beta_{i}-\varepsilon}{\sigma_{i}}\right)\right]^{D_{i 2}}\right\} \\
& \lambda^{-1 / 2} \phi\left(\varepsilon \lambda^{-1 / 2}\right) d \varepsilon .
\end{aligned}
$$

The log-likelihood for the $\mathrm{N}$ realizations of $\mathrm{D}_{\mathrm{ij}}$ and $\mathrm{y}_{\mathrm{i}}$ then is

$$
L L(\lambda)=\sum_{n=1}^{N} \ln L_{n}(\lambda) .
$$

The interpretation of (12) can be motivated by considering that $\varepsilon$, although unobserved, is treated as given for each observation. Since each $\varepsilon$ is i.i.d. $N(O, \lambda)$, 
then the joint probability function for $D_{i j}$ and $y_{i}$ can be marginalized with respect to $\varepsilon$ by integrating each observation over all values of $\varepsilon$. Unfortunately, it is this integration that renders the maximization of (13) computationally intensive. To evaluate (13), given the $k$ values of $\sigma_{1}, \sigma_{2}, \lambda, \beta_{1}$, and $\beta_{2}$, requires performing $N$ integrations. To calculate numerical first derivatives of (13), with respect to the $k$ unknown parameters, requires an additional $\mathrm{Nk}$ integrations. Further, there is little value to interchanging the order of integration and differentiation so that analytical derivatives may be employed because $\mathrm{Nk}$ integrations are still required. Nevertheless, the following application suggests that optimization of (13) is feasible using a microcomputer.

\section{DETERMINANTS OF RURAL RETAIL MARKET PARTICIPATION USING THE TWO-LIMIT TOBIT MODEL}

The bivariate two-limit tobit model is used to analyze the determinants of rural retail market participation. As Bresnahan and Reiss (1991) report, little is known about what determines where rural residents shop. A study in Douglas County, Nevada, surveyed 318 households and collected information on socioeconomic characteristics and shopping patterns. ${ }^{1}$ In particular, respondents were asked what percentage of grocery shopping was done in Douglas County $\left(y_{1}\right)$ and what percent of general merchandise (excluding clothing) purchases $\left(y_{2}\right)$ was made in the county.

In the case of grocery shopping, 44 respondents (14 percent) reported 0 percent and 49 respondents ( 15 percent) reported 100 percent of purchases made in the county. For general merchandise, 115 respondents ( 36 percent) reported 0 percent and 18 respondents (6 percent) reported 100 percent. Thus, the retail market participation variables contain a large number of observations at the two extremes of their ranges. This suggests that these variables are appropriately modeled as subject to double truncation.

The endogenous variables $y_{1}$ and $y_{2}$ were both scaled to lie within the range of 0 to 10 , therefore, $\mathrm{L}=10$. In the case of grocery shopping, variables thought to explain purchase patterns were related to income, where respondent and spouse work, and occupation. It was hypothesized that whether and where the respondent and spouse worked would have a relation to routine and frequent purchases such as for groceries. For general merchandise, income and respondents' work location were also considered potential determinants. Also, acquired tastes relating to age and education were investigated. These variables are described in Table 1.

Before estimation of the bivariate two-limit tobit model was attempted, the corresponding univariate models were estimated. This provided starting values for 
TABLE 1

Variable Definitions and Statistical Measures

Standard

Variable Definitions

Mean

Deviation

y1: Percentage of groceries purchased

in Douglas County. Scaled to lie

between 0 and 10 .

5.68

3.51

y2: Percentage of general merchandise (excluding

clothing) purchased in Douglas County.

Scaled to lie between 0 and 10 .

Income:

$\begin{array}{ll}\text { Value } & \begin{array}{l}\text { Category } \\ \text { Under } \$ 10,000\end{array} \\ 1.414 & \$ 10,000-\$ 20,000 \\ 1.732 & \$ 20,000-\$ 30,000 \\ 2 & \$ 30,000-\$ 40,000 \\ 2.236 & \$ 40,000-\$ 50,000 \\ 2.449 & \$ 50,000-\$ 60,000 \\ 2.646 & \$ 60,000-\$ 70,000 \\ 2.828 & \text { Over } \$ 70,000\end{array}$

1.96

0.46

1.414

Under $\$ 10,000$

Over $\$ 70,000$

Work in county: 1 if respondent has job

based in county, otherwise 0 .

0.43

0.50

Spouse works: 1 if respondent's spouse

works outside of the county, otherwise 0 .

0.73

0.44

Retired: 1 if respondent is retired, otherwise 0.

0.26

0.44

Age: 1 if respondent is more than 60 years old,

otherwise 0 .

0.28

0.45

the maximization of (13). The parameter $\lambda$ was set close to zero since as $\lambda \rightarrow 0$ the univariate and bivariate parameters coincide. The GAUSS programming language and its Gauss-Legendre integration procedure were used. Optimization was straightforward once it was observed that the order of integration needed to be set at its maximum level to insure sufficient accuracy in computing the first and second numerical derivatives.

Estimation results for both the univariate and bivariate models are presented in Table 2 . The standard errors are calculated in both cases using the formula by 
White (1982) in order to preserve robustness in the presence of distributional misspecification. Examination of the results in Table 2 shows the payoff to using a system's estimator is reflected in smaller standard errors on corresponding parameters (this need not be uniform, due to the use of White's formula). Furthermore, the absolute magnitudes of parameters seem to be slightly reduced for the bivariate model. A test of $\lambda=0$ may be used to discriminate between the univariate and systems estimators. Clearly this hypothesis is rejected at any conventional level of significance given the implied asymptotic $t$-value of 4.98. The likelihood ration test of this same hypothesis yields a test statistic of 41.6 , which is distributed as chi-square with one degree of freedom. The value of $\lambda$ and the error variances may be used to calculate the correlation of errors between the structural equations. It is computed to be $r=.400$ with associated asymptotic standard error of .060 .

Although the absolute magnitudes of parameters are somewhat smaller under the system's estimator, this does not necessarily imply smaller impacts from changes in the conditioning variables. To investigate this, the elements of $X_{1}$ and $\mathrm{X}_{2}$ were set at their most common values, and the conditional expectations of the endogenous variables were calculated. Specifically, $X_{1}$ was set with its intercept $=1$, income $=2$, spouse works $=1$, and other variables were zero. For $X_{2}$, its intercept $=1$, income $=2$, and other variables were zero. For the univariate models, evaluation of expression (8) led to the base levels $E\left[y_{1} / 0<y_{1}<L\right]$ $=4.810$ and $E\left[y_{2} \quad 10<y_{2}<L\right]$. To calculate similar expressions in the bivariate case requires marginalizing with respect to both $\varepsilon$ and the other endogenous variable before the analog to expression (8) can be evaluated. This resulted in base levels $E\left[y_{1} / 0<y_{1}<L\right]=4.783$ and $E\left[y_{2} / 0<y_{2}<L\right]=3.255$.

Table 3 provides information on how base levels change as conditioning variables are changed by discrete amounts. Using values in Table 2, Douglas County decision makers can gain insight conceming major retail demand determinants that impact the county's commercial sector. In comparing the univariate models to the bivariate two-limit tobit model, univariate models reveal attenuated effects due to changes in the conditioning variables relative to the bivariate model.

The increased sensitivity is primarily evident for the respondent who works in the county. For the grocery store single equation model, a respondent who works in Douglas County will increase local grocery purchases by 8.89 percent, which increases the bivariate model to 11.7 percent. Even more dramatic is the comparison of respondents who work in Douglas County and purchase general merchandise items locally. If the respondent worked in Douglas County, expected local general merchandise purchases increased by 16.6 percent, using the single equation model; however, using the bivariate model, local general merchandise expenditures increased by 22.3 percent if the respondent worked locally. 
TABLE 2

Single Equation and System Estimates.

\begin{tabular}{|c|c|c|c|c|}
\hline \multirow{3}{*}{$\begin{array}{l}\text { Parameters } \\
\text { Associated with }\end{array}$} & \multicolumn{4}{|c|}{ Estimated Parameters and Standard Errors } \\
\hline & \multicolumn{2}{|c|}{ Grocery Equation } & \multicolumn{2}{|c|}{ General Merch. Equation } \\
\hline & Single Equation ${ }^{2}$ & System $^{\mathrm{b}}$ & Single Equation ${ }^{2}$ & System $^{b}$ \\
\hline Intercept & $\begin{array}{c}3.297 \\
(1.866) c\end{array}$ & $\begin{array}{c}3.218 \\
(1.495)\end{array}$ & $\begin{array}{l}-1.517 \\
(1.443)\end{array}$ & $\begin{array}{l}-1.301 \\
(1.446)\end{array}$ \\
\hline Income & $\begin{array}{l}1.233 \\
(.699)\end{array}$ & $\begin{array}{l}1.200 \\
(.627)\end{array}$ & $\begin{array}{l}1.059 \\
(.673)\end{array}$ & $\begin{array}{c}.972 \\
(.671)\end{array}$ \\
\hline Work in county & $\begin{array}{l}1.272 \\
(.680)\end{array}$ & $\begin{array}{l}1.249 \\
(.615)\end{array}$ & $\begin{array}{l}2.018 \\
(.601)\end{array}$ & $\begin{array}{l}1.928 \\
(.593)\end{array}$ \\
\hline $\begin{array}{l}\text { Spouse works } \\
\text { outside of county }\end{array}$ & $\begin{array}{l}-1.327 \\
(.789)\end{array}$ & $\begin{array}{l}-1.101 \\
(.597)\end{array}$ & & \\
\hline Retired & $\begin{array}{l}1.674 \\
(.845)\end{array}$ & $\begin{array}{l}1.548 \\
(.729)\end{array}$ & & \\
\hline Age & & & $\begin{array}{l}2.330 \\
(.772)\end{array}$ & $\begin{array}{l}1.979 \\
(.730)\end{array}$ \\
\hline Education & & & $\begin{array}{r}-1.036 \\
(.594)\end{array}$ & $\begin{array}{l}-.744 \\
(.567)\end{array}$ \\
\hline$\sigma_{i i}$ & $\begin{array}{l}21.079 \\
(2.903)\end{array}$ & $\begin{array}{l}12.388 \\
(2.036)\end{array}$ & $\begin{array}{l}21.831 \\
(2.753)\end{array}$ & $\begin{array}{l}13.472 \\
(2.203)\end{array}$ \\
\hline$\lambda$ & & $\begin{array}{c}8.603 \\
(1.726)\end{array}$ & & $\begin{array}{c}8.603 \\
(1.726)\end{array}$ \\
\hline $\begin{array}{l}\text { Log-likelihood system } \\
\text { Single equation }\end{array}$ & $\begin{array}{l}-1407 \\
-1428\end{array}$ & & & \\
\hline
\end{tabular}

2Single equation model.

bystem equation model.

cStandard errors are in parentheses below associated coefficient. 
TABLE 3

Absolute and Percentage Changes in Conditional Expectations Caused by Changes in the Conditioning Variables.

\begin{tabular}{|c|c|c|c|c|}
\hline \multirow{3}{*}{$\begin{array}{l}\text { Variable and } \\
\text { Amount of Change }\end{array}$} & \multicolumn{4}{|c|}{ Absolute and Percentage Change } \\
\hline & \multicolumn{2}{|c|}{$E\left[y_{1} / 0<y_{1}<L\right]$} & \multicolumn{2}{|c|}{$E\left[y_{2} O_{<} y_{2}<L\right]$} \\
\hline & Single Equation & System & Single Equation & System \\
\hline Income $(+.2361)$ & $\begin{array}{c}.098 \\
(2.03 \%)\end{array}$ & $\begin{array}{c}.127 \\
(2.66 \%)\end{array}$ & $\begin{array}{c}.074 \\
(1.97 \%)\end{array}$ & $\begin{array}{c}.082 \\
(2.50 \%)\end{array}$ \\
\hline Work in County $(+1)$ & $\begin{array}{c}.428 \\
(8.89 \%)\end{array}$ & $\begin{array}{c}.561 \\
(11.7 \%)\end{array}$ & $\begin{array}{c}.604 \\
(16.6 \%)\end{array}$ & $\begin{array}{c}.727 \\
(22.3 \%)\end{array}$ \\
\hline Spouse Works $(-1)$ & $\begin{array}{c}.446 \\
(9.27 \%)\end{array}$ & $\begin{array}{c}.495 \\
(10.3 \%)\end{array}$ & & \\
\hline Retired (+1) & $\begin{array}{c}.562 \\
(11.7 \%)\end{array}$ & $\begin{array}{c}.694 \\
(14.5 \%)\end{array}$ & & \\
\hline Age (+1) & & & $\begin{array}{c}: 702 \\
(19.3 \%)\end{array}$ & $\begin{array}{c}.748 \\
(23.0 \%)\end{array}$ \\
\hline Education (+1) & & & $\begin{array}{c}-.284 \\
(-7.81 \%)\end{array}$ & $\begin{array}{c}-.252 \\
(-7.74 \%)\end{array}$ \\
\hline
\end{tabular}

Of additional interest to commercial sector activity is the impact on local retail expenditures if the spouse works in Douglas County. From the single equation model, expected grocery store sales would increase by 9.27 percent if the spouse worked in Douglas County; however, using the bivariate model, local grocery store sales increased by 10.3 percent if the spouse worked locally. Results from Table 3 indicate that Douglas County residents who work outside the county contribute substantially to grocery store and general merchandise sales leakages. Also comparing results between the univariate and bivariate models indicates purchase interdependencies among retail store types. Therefore, rural commercial sector development activities should be encouraged to be broad based rather than focusing on a single retail store type in order to capture retail purchase interdependencies. 


\section{CONCLUSIONS}

The trade area capture and two-limit tobit analysis suggest a number of objectives that could be pursued by Douglas County business interests and planners. Given the impact of lost local sales from Douglas County commuters who work in Carson City and Reno/Sparks, new entrants into the retail grocery market and general merchandising stores should locate at the extreme north end of the county. This location would allow the new entrants to more effectively compete with Carson City retailers for Douglas County resident sales, especially the Douglas County commuter sales. Locations at the northern end of the county would also offer the advantages of attracting shoppers from Carson City.

Similar location considerations come to play for other retail sales that have large sales leakages. Even though these leakages would be enough to support additional retail expansion in Douglas County, location near the northem end of the county would potentially maximize the market share of these new entrants because Douglas County residents would have to pass these retail stores on their way to work or to shopping centers in Carson City and Reno/Sparks.

Results of the bivariate two-limit tobit model indicate added sensitivity to changes in conditioning variables than the single equation approach. This result suggests that a more successful commercial sector development program should be focused not on one specific retail store, but or a broader array of retail stores to capture interdependencies of retail purchases.

\section{ENDNOTES}

1. The 318 households represent a 3 percent sample of households in Douglas County. The sample was stratified by place of residence in Douglas County so that respondent's place of residence is proportional to the populations of Douglas County's six major geographic areas: Lake Tahoe, Jack's Valley, Foothill area, East Valley, Gardnerville and Minden, and South Douglas County/Topez Lake.

\section{REFERENCES}

Bresnahan, T. F., and P. C. Reiss. "Entry and Competition in Concentrated Markets." Journal of Political Economy 99 (1991): 997-1009.

Chase, R., and G. Pulver. "The Impact of Shopping Centers on Downtowns of Small Nonmetropolitan Communities." Journal of the Community Development Society 14 (1983): 51-66. 
Chesher, A. "Score Tests for Zero Covariances in Recursive Linear Models for Grouped or Censored Data." Journal of Econometrics 28 (1985): 291-305.

Christaller, W. "Die Zentrulen Orte in Suddeutschland." Jena, Germany: Fisher, 1933. English translation by C. Baskin. The Central Places of Southern Germany. Englewood Cliffs, N.J.: Prentice-Hall, 1966.

Hamilton, J. Population Change and Retail Sales Patterns in Local Authority Areas of Queensland. Moscow, Idaho: University of Idaho, Department of Agricultural Economics, Ag. Econ. Research Paper \#369, 1981.

Hansen, N. Rural Poverty and the Urban Crisis. Bloomington, Ind.: Indiana University, 1970.

Harris, T. R. "Commercial Sector Development in Rural Communities: Trade Area Analysis." Corvallis: Westem Rural Development Center, Oregon State University, WREP-90,1985.

Henderson, D. "Rural Retail Sales and Consumer Expenditure Functions." The Journal of Agricultural Economics Research 42 (1990): 27-34.

Huang, C. J., F. A. Sloan, and K. W. Adamache. "Estimation of Seemingly Unrelated Tobit Regressions via the EM Algorithm." Journal of Business and Economic Statistics 5 (1987): 425-530.

Hustedde, R., G. Pulver, and R. Shaffer. Community Economic Analysis: A How to Book. Ames, Iowa: North Central Regional Center for Rural Development, 1984.

Johnson, N. L., and S. Kotz. Distributions in Statistics: Continuous Univariate Distributions - 1. Boston: Houghton Mifflin, 1970.

King, L. Central Place Theory. Beverly Hills, Calif.: Sage Publications, 1984.

Losch, H. The Economics of Location. New Haven, Conn.: Yale University Press, 1954.

Maddala, G. S. Limited-Dependent and Qualitative Variables in Econometrics. New York: Cambridge University Press, 1983.

McNamara, K., and G. Green. "Local and Regional Economic Development Planning and the Role of Community Development Practitioners." Journal of the Community Development Society 19 (1988): 42-55.

Nelson, F. D. "On a General Computer Algorithm for the Analysis of Models with Limited Dependent Variables." Annals of Economic and Social Measurement 5 (1976): 493-509.

Sales and Marketing Management Magazine. "Nevada Retail Sales by Store Group by County 1991." Survey of Buying Power (August 1992): C105C106.

Shaffer, R. Community Economics: Economic Structure and Change in Smaller Communities. Ames: Iowa State University Press, 1989. 
Stone, K. "Trade Area Analysis-A Catalyst for Community Development." Proceeding of the Community Economic Development Strategies Conference. Ames, Iowa: North Central Regional Center for Rural Development, 1988.

Stone, K., and J. McConnon. "Historical Analysis of Retail Sales of Britt and Surrounding Areas." Ames: Iowa State University, Iowa State Extension Fact Sheet, 1983.

Tweeten, L., and G. Brinkman. Micropolitan Development: Theory and Practice of Greater Rural Economic Development. Ames: The Iowa State University Press, 1976.

U.S. Department of Commerce. Regional Economic Information System. Bureau of Economic Analysis, 1992.

U.S. Department of Labor. Handbook of Labor Statistics. Bureau of Labor Statistics, Bulletin 2340, 1989.

White, H. "Maximum Likelihood of Misspecified Models." Econometrica 50 (1982):1-25.

Winder, R. "Economic Development and Social Change." Proceedings of Government Relations and Planning Conference. Washington, D.C.: American Institute of Planners, 1969.

Yanagida, J., B. Johnson, J. Young, and M. Lundeen. "An Analysis of Economic and Noneconomic Factors Affecting Retail Sales Leakages." The Review of Regional Studies 21 (1991): 53-64. 